\title{
Shorter telomeres associated with high doses of glucocorticoids: the link to increased mortality?
}

\author{
Anastasia P Athanasoulia-Kaspar ${ }^{1, *}$, Matthias K Auer, ${ }^{1,2, *}$, Günter K Stalla ${ }^{1}$ and Mira Jakovcevski ${ }^{3}$ \\ ${ }^{1}$ Clinical Neuroendocrinology, Max Planck Institute of Psychiatry, Munich, Germany \\ ${ }^{2}$ Medizinische Klinik und Poliklinik IV, Klinikum der Universität München, Ludwig-Maximilians-Universität München, Munich, Germany \\ ${ }^{3}$ Department of Stress Neurobiology and Neurogenetics, Max Planck Institute of Psychiatry, Munich, Germany \\ Correspondence should be addressed to A P Athanasoulia-Kaspar: anastasia.athanasoulia@hotmail.com \\ *(A P Athanasoulia-Kaspar and M K Auer contributed equally to this work)
}

\begin{abstract}
Objective: Patients with non-functioning pituitary adenomas exhibit high morbidity and mortality rates. Growth hormone deficiency and high doses of glucocorticoid substitution therapy have been identified as corresponding risk factors. Interestingly, high levels of endogenous cortisol in, e.g., patients with post-traumatic stress disorder or patients with Cushing's disease have been linked to shorter telomere length. Telomeres are noncoding DNA regions located at the end of chromosomes consisting of repetitive DNA sequences which shorten with aging and hereby determine cell survival. Therefore, telomere length can serve as a predictor for the onset of disease and mortality in some endocrine disorders (e.g., Cushing's disease).

Design/methods: Here, we examine telomere length from blood in patients $(n=115)$ with non-functioning pituitary adenomas (NFPA) in a cross-sectional case-control ( $n=106$, age-, gender-matched) study using qPCR. Linear regression models were used to identify independent predictors of telomere length.

Results: We show that patients with NFPA exhibited shorter telomeres than controls. No significant association of indices of growth hormone deficiency (IGF-1-level-SDS, years of unsubstituted growth hormone deficiency etc.) with telomere length was detected. Interestingly, linear regression analysis showed that hydrocortisone replacement dosage in patients with adrenal insufficiency $(n=52)$ was a significant predictor for shorter telomere length $(\beta=0.377 ; P=0.018)$ independent of potential confounders (gender, age, $\mathrm{BMI}$, arterial hypertension, systolic blood pressure, number of antihypertensive drugs, total leukocyte count, waist-to-hip ratio, waist circumference, diabetes mellitus type 2, HbA1c, current statin use). Median split analysis revealed that higher hydrocortisone intake (>20 mg) was associated with significantly shorter telomeres.

Conclusion: These observations strengthen the importance of adjusted glucocorticoid treatment in NFPA patients with respect to morbidity and mortality rates.
\end{abstract}

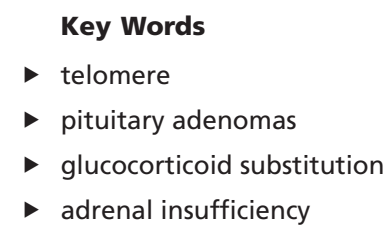

Endocrine Connections (2018) 7, 1217-1226

\section{Introduction}

Telomeres are noncoding DNA regions located at the end of chromosomes consisting of repetitive DNA sequences. Their primary purpose is to protect the chromosome from degradation processes and from loss of genetic material during cell division. When telomeres reach a critical short length, cell division is terminated and the corresponding https://ec.bioscientifica.com https://doi.org/10.1530/EC-18-0362
C) 2018 The authors Published by Bioscientifica Ltd

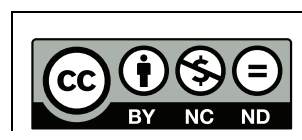

This work is licensed under a Creative Commons Attribution-NonCommercial-NoDerivatives 4.0 International License. 
cells undergo apoptosis (1). Telomerase, the key enzyme relevant for telomeric DNA synthesis and maintenance of telomere length (TL) is differently expressed in different tissue types and its expression levels depend on the status of the cell itself $(2,3,4,5)$. Differential telomerase activity is likely to account for differences in TL in distinct cell types of the human body. Nevertheless, blood TL is used as an easily accessible and well-established surrogate tissue for TL in other cells of the entire organism, especially when analyzing systemic effects of chronic diseases (6).

Typically, TL shortens with aging and shorter telomeres seem to be associated with age-related disease (7) as well as inflammatory states, cardiovascular disease, diabetes mellitus type 2 (DM2), poor lipid profile and high blood pressure $(8,9,10)$. Furthermore, a variety of factors such as epigenetic and environmental factors, including life style habits such as diet or smoking can influence and modulate telomerase activity (1).

Apart from the aforementioned conditions, another influential factor concerning TLs is hormones (11). Currently, pituitary tumors such as somatotropic and corticotropic adenomas resulting in hormone excess conditions such as acromegaly $(12,13)$ and Cushing's syndrome (13) have been associated with accelerated telomere shortening $(14,15)$, suggesting that TL length might be linked to the increased morbidity and mortality observed for both diseases $(16,17)$.

To the best of our knowledge, studies examining the TL in patients with non-functioning pituitary adenomas (NFPA), characterized by a high incidence of endocrine deficiencies, have not been conducted. However, taking into account that this patient group exhibits an increased morbidity and mortality (18) and the precise underlying mechanisms of this phenomenon have not been fully elucidated so far, TL studies in these patients could be very relevant. The higher morbidity and mortality in patients with NFPA has been attributed to cardiorespiratory and infectious diseases. Even though there is no consensus on predictive factors of mortality, high doses of glucocorticoid substitution therapy and older age at diagnosis are the most consistently identified risk factors associated with increased morbidity and mortality $(18,19)$. In addition, growth hormone deficiency (GHD) has been linked to mortality, although due to the retrospective character of these studies, there is still a debate if this relationship is causal $(20,21)$.

In the current study, we examined whether TL is shorter in patients with NFPA compared to controls and if so, how hormonal deficiencies and their replacement respectively affect TL.

\section{Materials and methods}

\section{Patients and control group}

We included 115 patients with NFPA treated in the Neuroendocrinology Unit of the Max Planck Institute of Psychiatry in Munich. Samples were retrieved from the biobank of the Network of Excellence for Neuroendocrine Tumors Munich (NeoExNET). All patients gave written informed consent and the study was approved by the Ethical Review Board of the Ludwig Maximilian University of Munich. The diagnosis of NFPA was based on clinical and laboratory findings as well as imaging studies and was confirmed by the pathological examination in patients who had undergone surgery. Clinical data, history of medication and comorbidities were collected retrospectively from patients' charts (Table 1 ).

Evaluation of pituitary function was based on basal measurements of thyroid-stimulating hormone (TSH), free thyroxine (FT4), free triiodothyronine (FT3), luteinizing hormone ( $\mathrm{LH})$, follicle-stimulating hormone (FSH) and total testosterone (in men) or estradiol (in women). Adrenal insufficiency was documented by ACTH stimulation test or insulin-tolerance test, whereas GHD by insulin-tolerance test or GHRH-arginine test. Additional parameters were assessed after an overnight fasting between 8:00 and 11:30h using routine clinical methods at the local laboratory of the Max Planck Institute of Psychiatry. Insulin-like growth factor 1 (IGF-1) and growth hormone (GH) were measured on the IMMULITE 2000 analyzer (Siemens). In women in the fertile age range, secondary hypogonadism was defined as the combination of low LH/FSH with secondary amenorrhea for at least 1 year. In women in the postmenopausal age range, secondary hypogonadism was documented when LH/FSH were inappropriately low for the postmenopausal age. In men, secondary hypogonadism was defined as a low testosterone level with an inappropriately low LH/FSH. Secondary hypothyroidism was defined as low FT4 combined with an inappropriately low serum TSH. Patients with adrenal insufficiency were treated with conventional hydrocortisone usually divided into 2-3 doses per day. Secondary hypothyroidism was treated with levothyroxine. Gonadotropic insufficiency was treated with testosterone in men (in form of transdermal gel or intramuscular injections) and with estrogen/progesterone replacement in women or in case of past hysterectomy with estradiol only. GHD was treated with recombinant human GH.

One hundred six controls were selected from a large control group previously recruited for the scope of another study (signed informed consent for the genetic analysis was also obtained from the controls) (22) and 
Table 1 Clinical and biochemical characteristics of NFPA patients and controls.

\begin{tabular}{|c|c|c|c|c|c|c|c|c|c|}
\hline & \multicolumn{4}{|c|}{ NPFA patients $(n=115)$} & \multicolumn{4}{|c|}{ Controls $(n=106)$} & \multirow[b]{3}{*}{$\boldsymbol{P}$} \\
\hline & \multicolumn{2}{|c|}{$N(\%)$} & \multirow[b]{2}{*}{ Mean } & \multirow[b]{2}{*}{ SDS } & \multicolumn{2}{|c|}{$N(\%)$} & \multirow[b]{2}{*}{ Mean } & \multirow[b]{2}{*}{ SDS } & \\
\hline & Valid & Missing & & & Valid & Missing & & & \\
\hline Age (years) & 115 & 0 & 57.7 & 16.76 & 106 & 0 & 58 & 14.79 & NS \\
\hline Gender (male) & $58(50.4)$ & 0 & n.a. & n.a. & 58 & 0 & n.a. & n.a. & NS \\
\hline Body mass index $\left(\mathrm{kg} / \mathrm{m}^{2}\right)$ & 115 & 0 & 28.28 & 5.28 & 104 & 0 & 26.5 & 4.2 & NS \\
\hline Current smokers & 14 & $10 *$ & n.a. & n.a. & 22 & $6 * *$ & n.a. & n.a. & NS \\
\hline Macroadenoma & $111(96.5)$ & 0 & n.a. & n.a. & n.a. & n.a. & n.a. & n.a. & n.a. \\
\hline Pituitary surgery & $106(92.2)$ & 0 & n.a. & n.a. & n.a. & n.a. & n.a. & n.a. & n.a. \\
\hline Radiotherapy & $17(14.7)$ & 0 & n.a. & n.a. & n.a. & n.a. & n.a. & n.a. & n.a. \\
\hline Diabetes mellitus type 2 & $12(10.4)$ & 0 & n.a. & n.a. & $2(1.9)$ & 2 & n.a. & n.a. & 0.011 \\
\hline Fasting glucose (mg/dL) & 100 & 15 & 86.5 & 15.63 & n.a. & n.a. & n.a. & n.a. & n.a. \\
\hline $\mathrm{HbA1c}(\%)$ & 94 & 21 & 5.53 & 0.64 & n.a. & n.a. & n.a. & n.a. & n.a. \\
\hline Pituitary insufficiency of any axis & $90(78.3)$ & 0 & n.a. & n.a. & n.a. & n.a. & n.a. & n.a. & n.a. \\
\hline GHD & $79(68.7)$ & 0 & n.a. & n.a. & n.a. & n.a. & n.a. & n.a. & n.a. \\
\hline GHD under substitution & $27(34)$ & 0 & n.a. & n.a. & n.a. & n.a. & n.a. & n.a. & n.a. \\
\hline Gonadotropic insufficiency & $51(44.3)$ & 0 & n.a. & n.a. & n.a. & n.a. & n.a. & n.a. & n.a. \\
\hline Hypothyroidism & $67(58.3)$ & 0 & n.a. & n.a. & n.a. & n.a. & n.a. & n.a. & n.a. \\
\hline $\begin{array}{l}\text { Adrenal insufficiency (all under } \\
\text { substitution with hydrocortisone) }\end{array}$ & 52 & 0 & n.a. & n.a. & n.a. & n.a. & n.a. & n.a. & n.a. \\
\hline Diabetes insipidus & $18(15.7)$ & 0 & n.a. & n.a. & n.a. & n.a. & n.a. & n.a. & n.a. \\
\hline Arterial hypertension & $45(39.1)$ & 0 & n.a. & n.a. & $18(16.9)$ & 2 & n.a. & n.a. & 0.001 \\
\hline Systolic blood pressure $(\mathrm{mmHg})$ & 108 & 7 & 135.74 & 20.44 & n.a. & n.a. & n.a. & n.a. & n.a. \\
\hline Diastolic blood pressure $(\mathrm{mmHg})$ & 108 & 7 & 84.95 & 13.35 & n.a. & n.a. & n.a. & n.a. & n.a. \\
\hline Waist circumference $(\mathrm{cm})$ & 85 & 30 & 95.69 & 13.23 & n.a. & n.a. & n.a. & n.a. & n.a. \\
\hline Hip circumference $(\mathrm{cm})$ & 78 & 37 & 105.5 & 18.72 & n.a. & n.a. & n.a. & n.a. & n.a. \\
\hline Waist-to-hip-ratio & 67 & 48 & 1.03 & 1.08 & n.a. & n.a. & n.a. & n.a. & n.a. \\
\hline Hypercholesterolemia/statin use & $31(27.0)$ & 0 & n.a. & n.a. & $14(13.2)$ & 2 & n.a. & n.a. & 0.016 \\
\hline Triglycerides (mg/dL) & 98 & 17 & 141.04 & 80.1 & n.a. & n.a. & n.a. & n.a. & n.a. \\
\hline Total cholesterol (mg/dL) & 110 & 5 & 209.26 & 40.69 & n.a. & n.a. & n.a. & n.a. & n.a. \\
\hline HDL cholesterol (mg/dL) & 95 & 20 & 59.35 & 18.65 & n.a. & n.a. & n.a. & n.a. & n.a. \\
\hline LDL cholesterol (mg/dL) & 94 & 21 & 138.95 & 35.05 & n.a. & n.a. & n.a. & n.a. & n.a. \\
\hline White blood cell count $\left(\times 10^{9} / \mathrm{L}\right)$ & 108 & 7 & 6.24 & 1.35 & n.a. & n.a. & n.a. & n.a. & n.a. \\
\hline IGF-1-SDS (ng/mL) & 100 & 15 & 136.75 & 72.99 & n.a. & n.a. & n.a. & n.a. & n.a. \\
\hline
\end{tabular}

GHD, growth hormone deficiency; n.a., non-applicable; NS, non-significant.

*In the NFPA group, 14 current smokers, 32 former smokers and 59 did never smoke; **In the control group, 22 current smokers, 34 former smokers and 44 did never smoke.

were matched for gender and age; the controls did not differ from NFPA patients regarding smoking status that is known to affect TL (Table 1). Furthermore, the presence of anxiety and affective disorders was excluded using the Composite International Diagnostic Screener. Metabolic comorbidities such as hypercholesterinemia, arterial hypertension and DM2 were provided by self-report. For nine patients, no corresponding matching partner could be identified explaining unequal group sizes.

Anthropometric parameters (weight, height, BMI and waist-to-hip ratio) were documented for the majority of the subjects. Hypertension was defined as systolic blood pressure $>140 \mathrm{mmHg}$ or diastolic blood pressure $>90 \mathrm{mmHg}$ or previous treatment with antihypertensive medications. DM2 was confirmed by fasting glucose $>126 \mathrm{mg} / \mathrm{dL}$ in two consecutive measurements or glucose $2 \mathrm{~h}$ after an oral tolerance test $>200 \mathrm{mg} / \mathrm{dL}$ or previous treatment with antidiabetic medications. Recorded biochemical parameters of lipid metabolism were total cholesterol, low-density lipoprotein (LDL), high-density lipoprotein (HDL) and triglycerides. Statin medication was noted (Table 1).

\section{TL measurement}

TL was assessed in genomic DNA (gDNA), derived from EDTA whole blood. Blood samples were kept at $4^{\circ} \mathrm{C}$ after blood draw. gDNA from patient and control blood samples was extracted using the Gentra Puregene Blood Kit (Qiagen) and stored at $4^{\circ} \mathrm{C}$. Samples were diluted to a concentration of $50 \mathrm{ng} / \mu \mathrm{L}$ and $\mathrm{TL}$ was measured by qPCR using a LightCycler FastStart DNA Master SYBR Green kit (Roche Diagnostics) on a LightCycler 96 Instrument (Roche Diagnostics). PCR reactions were run as quadruplicates, split between two different PCR plates with duplicates of each sample on every plate,

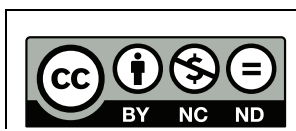

This work is licensed under a Creative Commons Attribution-NonCommercial-NoDerivatives 4.0 International License. 
using $1 \mu \mathrm{L}$ diluted gDNA per $10 \mu \mathrm{L}$ PCR reaction. The following primers were used in a final concentration of $0.25 \mu \mathrm{M}$, tel1b, 5'-CGGTTTGTTTGGGTTTGGGTTTGGG TTTGGGTTTGGGTT-3' and tel2b, 5'-GGCTTGCCTTAC CCTTACCCTTACCCTTACCCT TACCCT-3' for measuring TL, and 36B4u, 5'-CAGCAAGTGGGAAGGTGTAATCC-3' and 36B4d, 5'-CCCATTCTATCATCAACGGGTACAA-3', for the single-copy gene 36B4/RPLPO (encoding the 60S acidic ribosomal phosphoprotein $\mathrm{P0}$ ) as housekeeping primers (20). PCR conditions for telomere measurements were $10 \mathrm{~min}$ at $95^{\circ} \mathrm{C}$ for activation of the polymerase, followed by 30 amplification cycles of $95^{\circ} \mathrm{C}$ for $5 \mathrm{~s}, 56^{\circ} \mathrm{C}$ for $10 \mathrm{~s}$ and $72^{\circ} \mathrm{C}$ for $60 \mathrm{~s}$, and for the housekeeper: $10 \mathrm{~min}$ at $95^{\circ} \mathrm{C}$ for activation of the polymerase, followed by 40 amplification cycles of $95^{\circ} \mathrm{C}$ for $5 \mathrm{~s}, 58^{\circ} \mathrm{C}$ for $10 \mathrm{~s}$ and $72^{\circ} \mathrm{C}$ for $40 \mathrm{~s}$. To minimize batch effects, four samples of each batch were measured again together with the next batch. At the end of the entire experiment, an independent 'calibrator plate' containing four samples of each batch was run as well. First, mean Ct values for telomere and housekeeper measurements were normalized by their mean difference between repeated measurements on consecutive plates and on the 'calibrator plate'. Ct values for telomeres were further corrected with the housekeeper results and have been logarithmized $(\log 2)(23)$.

Measurement of TL is not trivial. Multiple studies have pointed to a pleiotropy of confounding factors, including sample storage and extraction methods $(24,25)$. We have made sure that all blood samples and resulting gDNA were handled, extracted and stored exactly in the same way. To test whether gDNA samples were of sufficiently consistent quality for telomere measurements, we determined telomere qPCR values for a subset of samples $(n=64)$ and correlated them with the age of the subjects. In line with previous reports of decreasing TL with age $(1,3)$, we found the TL to be highly negatively correlated with age $\left(r^{2}=0.45, P \leq 0.001\right.$, Fig. 1$)$, indicative of consistently suitable sample quality allowing us to obtain reliable qPCR results.

\section{Statistical methods}

Statistical analysis was conducted using SPSS 21.0. for Windows software (SPSS Inc). Demographic data are presented by means and standard deviations and frequencies. Data were examined for normality using histograms and, if skewed, were normalized by $\log$ transformation for further testing procedures. Descriptive statistics are presented as untransformed mean values for simplicity. A chi-square test was performed for

https://ec.bioscientifica.com

https://doi.org/10.1530/EC-18-0362 (c) 2018 The authors Published by Bioscientifica Ltd categorical variables. Fisher exact test was performed when appropriate. Univariate linear regression analysis was used as appropriate to estimate linear association between potential confounders with TL (age, gender, BMI, current smoking status (smoker vs no smoker), DM2 (yes/no), fasting glucose, HbA1c, arterial hypertension (yes/no), number of antihypertensive drugs, systolic and diastolic blood pressure, waist-to-hip-ratio, waist circumference, total leukocyte count, time since diagnosis (in months), pituitary insufficiency of any axis, overt sex steroid deficiency (unsubstituted gonadotropic deficiency + menopausal status not receiving replacement therapy) (yes/no), hypothyroidism, overt GHD (substituted GHD and unsubstituted GHD) (yes/no), growth hormone dose, IGF-1-SDS, adrenal insufficiency (yes/no), daily total hydrocortisone dose, diabetes insipidus (yes/no), triglycerides, current statin use (yes/no), total cholesterol and HDL/LDL cholesterol) (Table 2). Analysis of covariance (ANCOVA) was performed to evaluate TL between groups after adjustment for BMI, DM2, arterial hypertension and hypercholesterinemia.

A two-block linear regression analysis was carried out to assess the contribution of different variables to TL. For regression analysis, multiple imputation was used to fill in missing values based on the confirmation that the missing

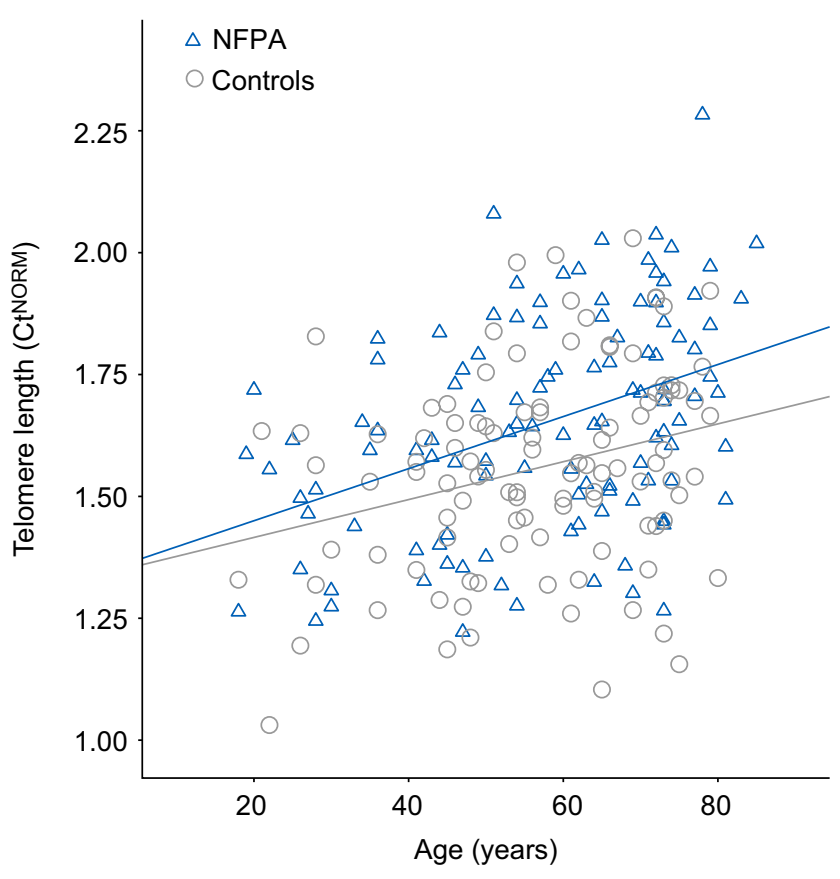

Figure 1

Shorter telomere length in NFPA patients. Correlation of adjusted pPCR values $(C t)$ with age in NFPA patients $(n=115)$ and controls $(n=106)$. Note, higher $\mathrm{Cts}$ are indicative of shorter telomeres. Pearson correlation: $r=0.404$, $P \leq 0.001$ (NFPA) and $r=0.282, P=0.003$ (controls). Ct, threshold cycle. 
pattern was completely at random (26). Five complete datasets were created, to compensate for the uncertainty caused by missing values (27). Subsequently, linear regression modeling was performed on each dataset, and the regression coefficients of the five models were pooled.

Block 1 included gender, age and BMI. A forced entry method was used for block 1 as we deemed inclusion of these variables, according to earlier studies, a basic requirement for our model. In the second block, we added those variables that had been identified in univariate regression analysis as showing a linear correlation at least on trend level $(P<0.1)$ with TL. All statistical tests were performed with $\alpha \leq 0.05$ (two-tailed).

\section{Results}

The clinical characteristics of the patients with NFPA and controls are presented in Table 1 . In the NFPA group, 111 patients presented with a macroadenoma and 106 had undergone surgery at least once. The mean time since first diagnosis was 132.8 months $( \pm 86.88)$. A total of 90 patients $(78.3 \%)$ presented with pituitary insufficiency of at least one axis (including adrenal, gonadotropic, somatotropic and thyrotropic insufficiency or diabetes insipidus). Herein, 79 (68.7\%) presented with GHD and $34 \%$ of them were under substitution with recombinant human GH; 51 (44.3\%) suffered from gonadotropic insufficiency and 67 (58.3\%) were hypothyroid (all on levothyroxine replacement), whereas 18 presented with diabetes insipidus and were under substitution with desmopressin and 52 patients were diagnosed with adrenal insufficiency and were under substitution with conventional hydrocortisone.

To investigate whether patients with NFPA exhibit shorter telomeres, we first compared them with ageand gender-matched controls. There were no statistical differences between the two groups regarding ratio of smoking or in terms of BMI compared to controls $\left(28.28 \mathrm{~kg} / \mathrm{m}^{2} \pm 5.28\right.$ vs $26.5 \pm 4.2 \mathrm{~kg} / \mathrm{m}^{2}, P=0.07$, Table 1$)$.

Table 2 Univariate correlation analysis of telomere length with clinical and biochemical characteristics of NFPA patients and controls.

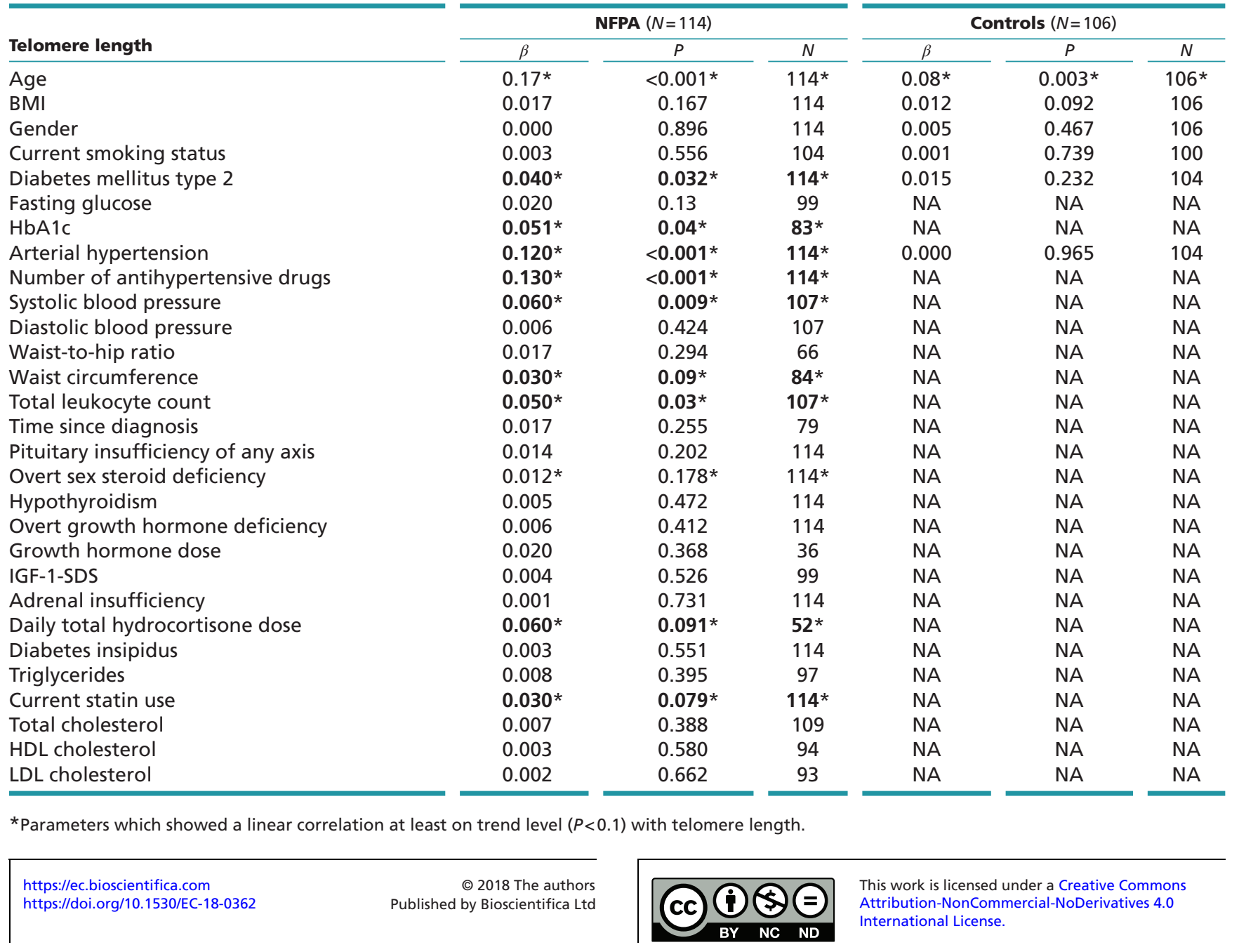


However, components of the metabolic syndrome such as hypercholesterolemia (27 vs $13.2 \% ; P=0.016$ ), arterial hypertension (39.1 vs $16.3 \%, P=0.001)$ and DM2 (10.4 vs $1.9 \%, P=0.011$ ) were more common in NFPA patients than in the control population.

We found that patients with NFPA had shorter telomeres compared to controls $\left(\mathrm{Ct}^{\text {Trans }} 1.65 \pm 0.22\right.$ vs $\left.\mathrm{Ct}^{\text {Trans }} 1.56 \pm 0.21, P=0.01\right)$. Note, typically, longer telomere templates contain more repeat regions and will create more PCR product in a shorter time, and therefore, lead to lower Ct values in qPCR applications. This difference remained significant when adjusting for hypercholesterolemia, arterial hypertension and DM2 by ANCOVA $(F=5.898, d f=3, P=0.001)$.

We conducted an explorative univariate regression analysis to define which variables could influence the TL and found that the following parameters showed a linear correlation at least on trend level $(P<0.1)$ with TL: age, DM2, HbA1c, arterial hypertension, number of antihypertensive drugs, systolic blood pressure, waist circumference, total leukocyte count, daily total hydrocortisone dose, current statin use (Table 2). In controls, with regard to available variables, there was only a significant correlation with age. As expected, there was a positive correlation of age with shorter TL in NFPA patients $(\beta=0.17 ; P \leq 0.001)$ and controls $(\beta=0.08, P=0.003)$. As indicated by the higher $\beta$-coefficient, telomere shortening seemed to be accelerated in the NFPA group in comparison to controls.

Parameters like BMI, gender, current smoking status, fasting glucose, diastolic blood pressure, waist-to-hip ratio, time since diagnosis, pituitary insufficiency of any axis, HbA1c, overt sex steroid deficiency, hypothyroidism, overt GHD, growth hormone dose, IGF-1, adrenal insufficiency, diabetes insipidus, triglycerides levels, total cholesterol, LDL and HDL cholesterol were not significant and were not included in the regression. The fully adjusted model (Block 2) explained $42.9 \%$ of the variance in TL according to the adjusted $R^{2}$ (Table 3 ). In the model, the 'best-fitting' variables were BMI $(\beta=-0.429 ; P=0.015)$, number of antihypertensive drugs $(\beta=0.404 ; P=0.014)$ and total HC dosage $(\beta=0.377 ; P=0.018)$.

Since we identified 'daily total hydrocortisone dose' as a significant independent factor of variance in the regression analysis, we compared patients with adrenal insufficiency with patients with intact corticotropic axis (Fig. 2). We found that there was no difference regarding TL between patients with and without hydrocortisone substitution. The two groups differ only in terms of basal glucose levels and diastolic blood pressure, but not in terms of BMI, age, white blood cell count, waist circumference or other parameters such as triglycerides, total cholesterol, HDL or LDL cholesterol or systolic blood pressure. There was no difference between TL of patients with intact GH axis and those with GHD under GH substitution and those with GHD and no treatment of growth hormone (data not shown).

To investigate the effect of hydrocortisone with a focused approach, we conducted a median split analysis in the group of patients with hydrocortisone substitution and we divided patients into two groups, i.e., one with patients who received a total daily hydrocortisone substitution of $20 \mathrm{mg}$ or less (Group $1-\mathrm{G} 1-n=43$, mean daily hydrocortisone dose $17.39 \pm 3.96 \mathrm{mg}$ ) and the other one with patients who received a dose higher than $20 \mathrm{mg}$ (Group 2-G2-n=9, mean daily hydrocortisone dose $27.78 \pm 5.07 \mathrm{mg}$ ). We found that patients in G2 on the higher hydrocortisone dose exhibited shorter telomeres than in group $1\left(\mathrm{G} 1 \mathrm{Ct}^{\text {Trans }} 1.63 \pm 0.21\right.$ vs G2 $\mathrm{Ct}^{\text {Trans }} 1.82 \pm 0.197, P=0.012$ ). Groups did not differ in fasting blood glucose levels, HbA1c, BMI, white blood cell count, waist-to-hip ratio, waist circumference, age, total cholesterol, HDL/LDL cholesterol, triglycerides, IGF-1SDS, diastolic or systolic blood pressure.

\section{Discussion}

Our initial hypothesis was that patients with NFPA exhibit accelerated telomere shortening due to different pituitary insufficiencies. To test this hypothesis, we compared TL of NFPA patients and controls and examined the influence of different pituitary insufficiencies including adrenal, gonadotropic and somatotropic. Indeed, we could demonstrate that patients with NFPA exhibit shorter telomeres than controls and that telomere shortening per year of age seems to be accelerated in these patients. Interestingly, among patients with pituitary insufficiencies, there was a clear association of higher hydrocortisone doses with shorter TL. To the best of our knowledge, this is the first study to evaluate TL in patients with NFPA.

TL serves as an early predictor of disease onset and all-cause mortality for numerous diseases. Several studies suggest that shorter telomeres are found in patients that exhibit a higher all-cause mortality and TLs appear to reflect the 'ability to survive' (28). Furthermore, short TLs may also be a risk factor for cardiovascular diseases as it is associated with metabolic disturbances such as high blood glucose and greater abdominal obesity, poor lipid profile, high systolic blood pressure, higher fasting glucose levels and smoking (29). 
Table 3 Regression analysis of determinants of telomere length in NFPA patients.

\begin{tabular}{|c|c|c|c|c|}
\hline \multirow[b]{2}{*}{ Determinant variables } & \multicolumn{4}{|c|}{ Telomere length (TL) } \\
\hline & $\beta$ & $P$ (variable) & Adjusted $R^{2}$ & $P$ (model) \\
\hline Block 1 & & & 0.22 & $<0.001$ \\
\hline Gender & 0.042 & 0.812 & & \\
\hline $\mathrm{Age}^{\mathrm{b}}$ & 0.465 & 0.005 & & \\
\hline $\mathrm{BMI}^{\mathrm{b}}$ & -0.224 & 0.206 & & \\
\hline Block $2^{a}$ & & & 0.429 & $<0.001$ \\
\hline Gender & -0.231 & 0.2 & & \\
\hline $\operatorname{Age}^{b}$ & 0.297 & 0.051 & & \\
\hline $\mathrm{BMI}^{\mathrm{b}}$ & -0.429 & 0.015 & & \\
\hline Number of antihypertensive drugs & 0.404 & 0.014 & & \\
\hline Daily total HC dose & 0.377 & 0.018 & & \\
\hline
\end{tabular}

Multiple imputation was used to fill in missing values based on the confirmation that the missing pattern was completely at random. Five complete datasets were created, to compensate for the uncertainty caused by missing values. Subsequently, linear regression modeling was performed on each dataset, and the regression coefficients of the five models were pooled.

aBlock 1 + diabetes mellitus type 2, HbA1c, arterial hypertension, number of antihypertensive drugs, systolic blood pressure, waist circumference, total leucocyte count, current statin use + daily total HC dose; 'logarithmized. $\beta$, standardized beta coefficient.

Patients with NFPA have higher mortality rates in comparison to the general population, although studies assessing mortality in these patients are limited. Standardized mortality ratios have been reported to be significantly increased in female NFPA patients as compared to male NFPA patients as well as in patients treated with radiotherapy; they are mostly attributed to infectious and cardio/cerebrovascular diseases (30, 31 ). The role of age at diagnosis as a predictive factor of mortality is discussed controversially. Whereas some studies suggest a positive correlation of age at diagnosis and mortality $(32,33)$, Olsson et al. (2015) come to the opposite conclusion that age of 40 years and earlier is a predictor of mortality (31).

Regarding pituitary hormone deficiencies and their influence on mortality, empirical findings are confounded by differences in the diagnostic and hormone substitution protocols between different study centers over the years. In the present study, we could show that neither somatotropic nor gonadotropic deficiency plays any role concerning TL. Taking into consideration that there is a clear link between TL and mortality, our results do not support the association between somatotropic or gonadotropic deficiency and higher mortality, either. Indeed, previous data suggest that GH-deficient patients are not at increased risk of death compared to those with intact $\mathrm{GH}$ secretion $(32,34)$. However, concerning gonadotropic deficiency, data on mortality rates have been inconsistent. According to at least one study, gonadotropin-deficient patients showed higher mortality, an association that remained significant only for men after adjustment for dysfunction of other pituitary axes and sub-analysis of gonadotropin deficiency according to sex (34). However, Ntali et al. (2016) could not confirm that unsubstituted gonadotropic deficiency poses a risk for mortality.

In the present study, we clearly demonstrated that NFPA patients with adrenal insufficiency under hydrocortisone substitution did not show shorter telomere compared to those with intact corticotropic axis. Our results are in accordance with data presenting that adrenal deficiency per se is no risk for increased mortality when patients are treated with lower dose (up to $20 \mathrm{mg}$ ) of hydrocortisone $(19,32)$. Here we show, for the first

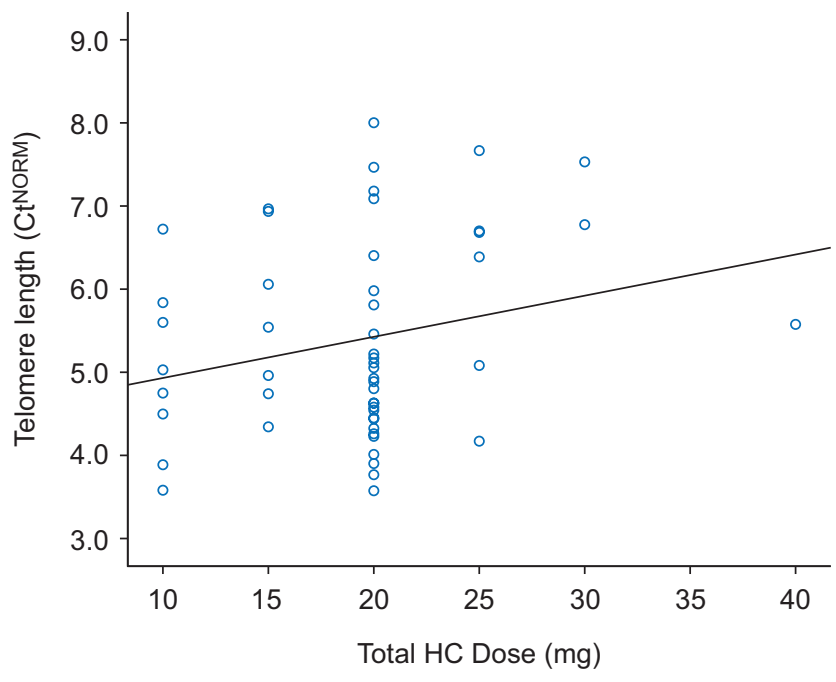

Figure 2

Telomere length in NFPA depends on the dose of glucocorticoid replacement therapy. Correlation of adjusted PPCR values $(\mathrm{Ct})$ with daily total hydrocortisone dose in NFPA patients with adrenal insufficiency $(n=52)$. Note, higher $\mathrm{Cts}$ are indicative of shorter telomeres. Pearson correlation: $B=0.060, P=0.091$. $C t$, threshold cycle. https://ec.bioscientifica.com

https://doi.org/10.1530/EC-18-0362 (c) 2018 The authors Published by Bioscientifica Ltd
This work is licensed under a Creative Commons Attribution-NonCommercial-NoDerivatives 4.0 International License. 
time that the dose of daily hydrocortisone substitution is linked to TL in NFPA and that patients with a higher daily hydrocortisone dose (above $20 \mathrm{mg}$ ) presented with shorter telomeres. Our findings are in agreement with recent data showing increased overall mortality in patients with NFPA on higher glucocorticoid replacement. Mortality risk in the study of Hammarstrand et al. (2017) was higher for patients receiving a daily hydrocortisone dose of more than $20 \mathrm{mg}$ compared to subjects with daily hydrocortisone doses of $\leq 20 \mathrm{mg}$, to patients without glucocorticoid replacement and to the general population (35).

Moreover, our results are in accordance with studies that clearly associate hypercortisolism as in Cushing's syndrome with shorter telomeres (14) and demonstrate that patients with active Cushing's syndrome have shorter TL than those patients who underwent successful therapy of hypercortisolism (36). Furthermore, TL has been evaluated in other conditions with increased endogenous cortisol such as chronic stress exposure and post-traumatic stress disorder (37). Shorter TL has been reported for both neuropsychiatric conditions, notwithstanding the influence of their complex interactions with other chronic diseases on telomere dynamics (37).

In line with those in vivo findings are studies showing that exposure to high hydrocortisone levels in vitro results in a 50\% reduction of telomerase activity in T-lymphocytes $(38,39)$, clearly suggesting a direct effect of cortisol on TL. However, the underlying mechanism of how high hydrocortisone doses induce telomere shortening remains unresolved. Hypercortisolism seems to contribute to premature aging by inducing accelerated telomere shortening, which might be an explanation for persistent high morbidity and other clinical consequences associated with Cushing's disease, even years after successful treatment for hypercortisolism.

This study has a few limitations. On the one hand, our control group was chosen from a bigger collective of controls after excluding patients with anxiety and depression. We addressed this problem by matching patients post hoc with the appropriate controls. The two groups were matched for the known possible confounding factors, i.e., age, gender and smoking status. However, presence of metabolic diseases in controls was only available by self-report, and are therefore likely to be underreported. Other confounding factors such as endogenous glucocorticoid exposure could not be excluded in this control group.

As for any cross-sectional study, causality cannot be inferred. Herein, future studies, beyond the scope of this study, need to address causality using, e.g., cortisol-treated NFPA patient cells. However, the discussed limitations are much more likely to have led to an underestimation of our effect sizes than to create false-positive findings. Finally, it might be of interest to see, if TL in this particular patient group is indeed predictive for increased mortality.

In summary, we demonstrated for the first time a significant difference between the TL of patients with NFPA and controls. Moreover, we showed a clear association of higher hydrocortisone doses with shorter TL in these patients, which further underlines the great importance of a balanced and adjusted glucocorticoid replacement therapy in NFPA patients.

\section{Declaration of interest}

$\mathrm{M} \mathrm{K} \mathrm{A} \mathrm{has} \mathrm{received} \mathrm{consultancy} \mathrm{fees} \mathrm{from} \mathrm{Shire} \mathrm{and} \mathrm{has} \mathrm{been} \mathrm{reimbursed}$ conference delegate fees, participant fees for educational events and travel expenses by Pfizer, Ipsen and Lilly. A P A-K has been reimbursed conference delegate fees by Pfizer, Novartis and Sandoz. G K S has received consultancy fees and has been reimbursed conference delegate fees, participant fees for educational events and travel expenses from Pfizer, Ipsen, Lilly, Shire, Novartis, Sandoz, NovoNordisk and HRA. M J does not declare any conflict of interest.

\section{Funding}

M J was supported by a NARSAD Young Investigator grant of the Brain \& Behavior foundation (New York City, NY, USA). This work was supported by Pfizer (grant number WI196186-INSPIIRE).

\section{Author contribution statement}

$M K A$ and $G K S$ initially conceived the study. M K A, A P A-K and M J planned the study. M K A and M J analyzed data. A P A-K, M K A and M J wrote the paper.

\section{Acknowledgements}

The authors thank Dr Sandra Fill for her contribution in collecting the data, Alina Trontsch for managing and storing gDNA samples within the Biobank at the Max Institute of Psychiatry (Munich, Germany) and Prof. Dr Johannes Kaspar for his valuable contribution in improving the manuscript.

\section{References}

1 Calado RT \& Young NS. Telomere diseases. New England Journal of Medicne 2009361 2353-2365. (https://doi.org/10.1056/ NEJMra0903373)

2 Lin KW \& Yan J. The telomere length dynamic and methods of its assessment. Journal of Cellular and Molecular Medicine 20059 977-989. (https://doi.org/10.1111/j.1582-4934.2005.tb00395.x)

3 Takubo K, Aida J, Izumiyama-Shimomura N, Ishikawa N, Sawabe M, Kurabayashi R, Shiraishi H, Arai T \& Nakamura K. Changes of telomere length with aging. Geriatrics and Gerontology International 201010 S197-S206. (https://doi.org/10.1111/j.14470594.2010.00605.x)

4 Aubert G \& Lansdorp PM. Telomeres and aging. Physiological Reviews 200888 557-579. (https://doi.org/10.1152/physrev.00026.2007)

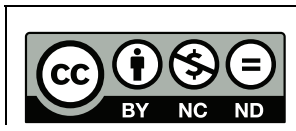

This work is licensed under a Creative Commons Attribution-NonCommercial-NoDerivatives 4.0 International License. 
5 Zhu H, Belcher M \& van der Harst P. Healthy aging and disease: role for telomere biology? Clinical Science 2011120 427-440. (https://doi. org/10.1042/CS20100385)

6 Friedrich U, Griese E, Schwab M, Fritz P, Thon K and Klotz U. Telomere length in different tissues of elderly patients. Mechanisms of Ageing and Development 2000119 89-99. (https://doi.org/10.1016/ S0047-6374(00)00173-1)

7 Mason PJ \& Perdigones N. Telomere biology and translational research. Translational Research 2013162 333-342. (https://doi. org/10.1016/j.trsl.2013.08.009)

8 Fuster JJ \& Andrés V. Telomere biology and cardiovascular disease. Circulation Research 200699 1167-1180. (https://doi.org/10.1161/01. RES.0000251281.00845.18)

9 Salpea KD, Talmud PJ, Cooper JA, Maubaret CG, Stephens JW, Abelak K \& Humphries SE. Association of telomere length with type 2 diabetes, oxidative stress and UCP2 gene variation. Atherosclerosis 2010209 42-50. (https://doi.org/10.1016/j. atherosclerosis.2009.09.070)

10 Harte AL, da Silva NF, Miller MA, Cappuccio FP, Kelly A, O'Hare JP, Barnett AH, Al-Daghri NM, Al-Attas O, Alokail M, et al. Telomere length attrition, a marker of biological senescence, is inversely correlated with triglycerides and cholesterol in South Asian males with type 2 diabetes mellitus. Experimental Diabetes Research 2012; 2012 895185. (https://doi.org/10.1155/2012/895185)

11 Bayne S \& Liu JP. Hormones and growth factors regulate telomerase activity in ageing and cancer. Molecular and Cellular Endocrinology 2005240 11-22. (https://doi.org/10.1016/j.mce.2005.05.009)

12 Dekkers OM, Biermasz NR, Pereira AM, Romijn JA, Vandenbroucke JP. Mortality in acromegaly: a metaanalysis. Journal of Clinical Endocrinology and Metabolism 200893 61-67. (https://doi. org/10.1210/jc.2007-1191)

13 Romijn JA. The chronic syndromes after previous treatment of pituitary tumours. Nature Reviews Endocrinology 201612 547-556. (https://doi.org/10.1038/nrendo.2016.84)

14 Aulinas A, Ramírez MJ, Barahona MJ, Valassi E, Resmini E, Mato E, Santos A, Crespo I, Bell O, Surrallés J, et al. Dyslipidemia and chronic inflammation markers are correlated with telomere length shortening in Cushing's syndrome. PLOS ONE 201510 e0120185. (https://doi.org/10.1371/journal.pone.0120185)

15 Matsumoto R, Fukuoka H, Iguchi G, Odake Y, Yoshida K, Bando H Suda K, Nishizawa H, Takahashi M, Yamada S, et al. Accelerated telomere shortening in acromegaly; IGF-I induces telomere shortening and cellular senescence. PLOS ONE 201510 e0140189. (https://doi.org/10.1371/journal.pone.0140189)

16 Pivonello R, Auriemma RS, Grasso LF, Pivonello C, Simeoli C, Patalano R, Galdiero M \& Colao A. Complications of acromegaly: cardiovascular, respiratory and metabolic comorbidities. Pituitary 201720 46-62. (https://doi.org/10.1007/s11102-017-0797-7)

17 Pivonello R, Isidori AM, De Martino MC, Newell-Price J, Biller BM \& Colao A. Complications of Cushing's syndrome: state of the art. Lancet Diabetes and Endocrinololgy 20164 611-629. (https://doi. org/10.1016/S2213-8587(16)00086-3)

18 Tampourlou M, Fountas A, Ntali G \& Karavitaki N. Mortality in patients with non-functioning pituitary adenoma. Pituitary 201821 203-207. (https://doi.org/10.1007/s11102-018-0863-9)

19 Zueger T, Kirchner P, Herren C, Fischli S, Zwahlen M, Christ E \& Stettler C. Glucocorticoid replacement and mortality in patients with nonfunctioning pituitary adenoma. Journal of Clinical Endocrinology and Metabolism 201297 E1938-E4192. (https://doi.org/10.1210/ jc.2012-2432)

20 Svensson J \& Bengtsson BA. Safety aspects of GH replacement. European Journal of Endocrinology 2009161 S65-S74. (https://doi org/10.1530/EJE-09-0287)

21 Dekkers OM, Biermasz NR, Pereira AM, Roelfsema F, van Aken MO, Voormolen JH, Romijn JA. Mortality in patients treated for Cushing's disease is increased, compared with patients treated for nonfunctioning pituitary macroadenoma. Journal of Clinical Endocrinology and Metabolism 200792 976-981. (https://doi. org/10.1210/jc.2006-2112)

22 Lucae S, Salyakina D, Barden N, Harvey M, Gagné B, Labbé M, Binder EB, Uhr M, Paez-Pereda M, Sillaber I, et al. P2RX7, a gene coding for a purinergic ligand-gated ion channel, is associated with major depressive disorder. Human Molecular Genetics $2006 \mathbf{1 5}$ 2438-2445. (https://doi.org/10.1093/hmg/ddl166)

23 Gil ME \& Coetzer TL. Real-time quantitative PCR of telomere length. Molecular Biotechnology 200427 169-172. (https://doi.org/10.1385/ MB:27:2:169)

24 Zanet DL, Saberi S, Oliveira L, Sattha B, Gadawski I \& Côté HC. Blood and dried blood spot telomere length measurement by qPCR: assay considerations. PLoS ONE 20138 e57787. (https://doi.org/10.1371/ journal.pone.0057787)

25 Visvikis S, Schlenck A \& Maurice M. DNA extraction and stability for epidemiological studies. Clinical Chemistry and Laboratory Medicine 199836 551-555. (https://doi.org/10.15 15/CCLM.1998.094)

26 Donders AR, van der Heijden GJ, Stijnen T \& Moons KG. Review: a gentle introduction to imputation of missing values. Journal of Clinical Epidemiology 200659 1087-1091. (https://doi.org/10.1016/j. jclinepi.2006.01.014)

27 Gladitz J. Rubin, Donald B.: Multiple Imputation for Nonresponse in Surveys. John Wiley \& Sons, Chichester - New York - Brisbane - Toronto - Singapore 1987, xxx, 258 S., 6 Abb., £ 30.25, ISSN 0271-6232. Biometrical Journal 198931 131-132. (https://doi. org/10.1002/bimj.4710310118)

28 Cawthon RM, Smith KR, O’Brien E, Sivatchenko A \& Kerber RA. Association between telomere length in blood and mortality in people aged 60 years or older. Lancet $2003361393-395$. (https://doi. org/10.1016/S0140-6736(03)12384-7)

29 Willeit P, Willeit J, Brandstätter A, Ehrlenbach S, Mayr A, Gasperi A, Weger S, Oberhollenzer F, Reindl M, Kronenberg F, et al. Cellular aging reflected by leukocyte telomere length predicts advanced atherosclerosis and cardiovascular disease risk. Arterio-Sclerosis, Thrombosis, and Vascular Biology 201030 1649-1656. (https://doi. org/10.1161/ATVBAHA.110.205492)

30 Tomlinson JW, Holden N, Hills RK, Wheatley K, Clayton RN, Bates AS, Sheppard MC \& Stewart PM. Association between premature mortality and hypopituitarism. West Midlands Prospective Hypopituitary Study Group. Lancet 2001357 425-431. (https://doi. org/10.10 16/S0140-6736(00)04006-X)

31 Olsson DS, Nilsson AG, Bryngelsson IL, Trimpou P, Johannsson G $\&$ Andersson E. Excess mortality in women and young adults with nonfunctioning pituitary adenoma: a Swedish nationwide study. Journal of Clinical Endocrinology and Metabolism 2015100 2651-2658. (https://doi.org/10.1210/jc.2015-1475)

32 Ntali G, Capatina C, Fazal-Sanderson V, Byrne JV, Cudlip S, Grossman AB, Wass JA \& Karavitaki N. Mortality in patients with non-functioning pituitary adenoma is increased: systematic analysis of 546 cases with long follow-up. European Journal of Endocrinology 2016174 137-145. (https://doi.org/10.1530/EJE-15-0967)

33 Chang EF, Zada G, Kim S, Lamborn KR, Quinones-Hinojosa A, Tyrrell JB, Wilson CB \& Kunwar S. Long-term recurrence and mortality after surgery and adjuvant radiotherapy for nonfunctional pituitary adenomas. Journal of Neurosurgery 2008108 736-745. (https://doi.org/10.3171/JNS/2008/108/4/0736)

34 O'Reilly MW, Reulen RC, Gupta S, Thompson CA, Dineen R, Goulden EL, Bugg G, Pearce H, Toogood AA, Gittoes NJ, et al. ACTH and gonadotropin deficiencies predict mortality in patients treated for nonfunctioning pituitary adenoma: long-term follow-up of 519 patients in two large European centres. Clinical Endocrinology $2016 \mathbf{8 5}$ 748-756. (https://doi.org/10.1111/cen.13141)

35 Hammarstrand C, Ragnarsson O, Hallén T, Andersson E, Skoglund T, Nilsson AG, Johannsson G \& Olsson DS. Higher glucocorticoid replacement doses are associated with increased mortality in patients
This work is licensed under a Creative Commons Attribution-NonCommercial-NoDerivatives 4.0 International License. 
with pituitary adenoma. European Journal of Endocrinology 2017177 251-256. (https://doi.org/10.1530/EJE-17-0340)

36 Aulinas A, Ramírez MJ, Barahona MJ, Valassi E, Resmini E, Mato E, Santos A, Crespo I, Bell O, Surrallés J, et al. Telomere length analysis in Cushing's syndrome. European Journal of Endocrinology 2014171 21-29. (https://doi.org/10.1530/EJE-14-0098)

37 Aulinas A, Ramírez MJ, Barahona MJ, Mato E, Bell O, Surrallés J \& Webb SM. Telomeres and endocrine dysfunction of the adrenal and
GH/IGF-1 axes. Clinical Endocrinology 201379 751-759. (https://doi. org/10.1111/cen.12310)

38 Epel ES. Psychological and metabolic stress: a recipe for accelerated cellular aging? Hormones 20098 7-22.

39 Choi J, Fauce SR \& Effros RB. Reduced telomerase activity in human T lymphocytes exposed to cortisol. Brain, Behavior, and Immunity 200822 600-605. (https://doi.org/10.1016/j. bbi.2007.12.004)

\section{Received in final form 27August2018}

Accepted 30August2018

Accepted Preprint published online 31August2018
This work is licensed under a Creative Commons Attribution-NonCommercial-NoDerivatives 4.0 International License. 